\title{
A CIÊNCIA DO MARKETING: A INFLUÊNCIA DA FILOSOFIA E DAS CIÊNCIAS NOS PRIMEIROS ESTUDOS EM MARKETING
}

SÉRGIO LUIS IGNÁCIO DE OLIVEIRA ANHEMBI MORUMBI SÃO PAULO, BRASIL MARKETING@UOL.COM.BR

LEANDRO JANUÉRIO DE SOUZA UNIVERSIDADE PAULISTA SÃO PAULO, BRASIL LEANDRO.JANUARIO@BOL.COM.BR HTTP://DX.DOI.ORG/10.5902/2316882X25668 


\section{A CIÊNCIA DO MARKETING: A INFLUÊNCIA DA FILOSOFIA E DAS CIÊNCIAS NOS PRIMEIROS ESTUDOS EM MARKETING}

Resumo: Este ensaio teórico tem como objetivo entender a influência da filosofia e das ciências nos primeiros estudos em Marketing no início do século XX. Por meio de uma pesquisa historiográfica em documentos do período, procuramos demonstrar como os primeiros pesquisadores da época se apoiaram em uma metodologia cientifica, nos mesmos moldes das ciências mais sedimentadas para garantir a sua importância tanto nos meios acadêmicos como empresarial.

Palavras-chave: Positivismo; Racionalidade \& Marketing; Centros de Pesquisa.

CIENCIA DEL MARKETING: LA INFLUENCIA DE LA FILOSOFÍA Y DE LA CIENCIA EN LOS PRIMEROS ESTUDIOS DE MARKETING

Resumen: En este ensayo teórico tiene como objetivo comprender la influencia de la filosofía y de la ciencia en los primeros estudios en Marketing a principios del siglo XX. A través de una investigación histórica en los documentos de la época para demostrar cómo los primeros investigadores de tiempo se han basado en una metodología científica, en el sentido de las ciencias sedimentadas para asegurar su importancia tanto en el ámbito académico y empresarial.

Palabras clave: Positivismo; La racionalidad y Marketing; Centros de investigación.

\section{THE SCIENCE OF MARKETING: THE INFLUENCE OF PHILOSOPHY} AND SCIENCE IN THE FIRST STUDIES IN MARKETING

Abstract: This theoretical essay aims to understand the influence of philosophy and science in the early studies in Marketing in the early twentieth century. Through a historiographical research in documents of the period we tried to demonstrate how the first researchers of the time were based on a scientific methodology, in the same way of the sciences most sedimentadas to guarantee its importance in the academic as well as the business.

Keywords: Positivism; Rationality \& Marketing; Research Center. 


\section{INTRODUÇÃO}

Marketing é a disciplina, ou área de conhecimento, que tem como objetivo estratégico estudar os relacionamentos, comerciais ou não, entre empresas e consumidores com o objetivo de entender as suas necessidades e transformá-las em um produto, serviço ou ideia que será disponibilizado ao mercado, ou, como um dos conceitos usuais, a busca pela empresa em satisfazer as necessidades e desejos dos consumidores e de seus stakeholders (KOTLER \& KELLER, 2012; COBRA, 1992; OLIVEIRA, 2007). Também, como conceituado pela AMA - American Marketing Association :"Marketing is the activity, set of institutions, and processes for creating, communicating, delivering, and exchanging offerings that have value for customers, clients, partners, and society at large." (AMA, 2016). Devido ao foco no entendimento dos consumidores, torna-se, atualmente, uma importante área de saber, tanto no ambiente empresarial como acadêmico.

Essa forma de relacionamento com o mercado nem sempre foi o objetivo dos pesquisadores e dos gestores mercadológicos. Em seus primórdios, mais precisamente nas primeiras décadas no século passado, o propósito das pesquisas acadêmicas posteriormente aplicadas ao mercado, era a distribuição, o seu processo estratégico, e os agentes envolvidos nesse relacionamento.

Essa visão metodológica e estratégica ocorreu devido à necessidade, por parte das organizações, em escoar os produtos fabricados em larga escala pelas empresas que surgiam em território norte-americano, especificamente no final no final do século XIX e início do século XX, fruto dos avanços tecnológicos proporcionados pela $2^{\mathrm{a}}$. revolução industrial (AJZENTAL , 2008;ARANTES, 1975; BARTELS, 1951; BARTELS, 1974; GRISI, GRISI \& SANTOS, 1983;LAZER, 1966; LITTLE, 1970; MAYNARD, 1941; MORE \& WILKIE, 2003; SANDHUSSEN, 2003; SAVITT, 1980; SURFACE, 1957; VARGO \& LUSCH, 2004).

Nesse período houve um vultoso nascimento de empresas em decorrência da melhoria dos processos de fabricação, padronização e racionalização das tarefas e, ao mesmo tempo, um crescimento das empresas já existentes, tanto em termos de quantidade produzida e do tamanho e complexidade dos agentes envolvidos em seu processo produtivo (ANDERSON \& NARUS, 1990; DINIZ, 2016; HOBSBAWM, 2002; LAS CASAS, 2001; MELANDRI, 2000). Foram mudanças consideráveis no contexto em-

Rev.Cad.Comun. Santa Maria, v.22, n.1, art 9, p.201 de 224, jan/abr.2018 
presarial, alterando o cenário econômico e social em território norte-americano, e consequentemente o seu relacionamento entre as empresas e o mercado.

O período é balizado pelos primeiros estudos sistematizados em Marketing, isto é, o período no qual os problemas mercadológicos foram organizados em uma área do saber, com centros de pesquisa promovendo estudos para tratar os assuntos de distribuição, obras sendo publicadas e cursos sendo oferecidos. Esses estudos foram elaborados em universidades norte-americanas, por pesquisadores, acadêmicos pertencentes as cadeiras de economia e administração, interessados em examinar e discutir os problemas de distribuição que surgiram em decorrência da emergente produção em massa fruto dos avanços proporcionados pela $2^{a}$. revolução industrial (BARTELS, 1951A; 1960; 1968).

O objetivo desses primeiros acadêmicos era melhorar as práticas vigentes de distribuição da produção nos setores agrícola e industrial, devido a constatação que, com melhores formas de distribuição, as organizações acrescentariam um diferencial competitivo em relação aos seus concorrentes e, poderiam agregar valor aos consumidores que começavam a surgir na economia norte-americana.

Dessa forma, na percepção dos problemas relacionados a distribuição que se tornavam latentes, e com o aumento dos profissionais que trabaIhavam no mercado e presenciavam in loco este fenômeno (ANDERSON \& NARUS, 1990; BARTLES, 1976; BAUMOL, 1957; BUTLER, 1914; CHERINGTON, 1921; MORE \& WELKIE, 2003), passou a existir um número maior de pesquisadores e instituições dedicadas a entender as transformações ocorridas no contexto organizacional, que modificaram o relacionamento entre empresas e seus consumidores (SAVITT, 1980).

Com uma crescente procura por pesquisas para entender, e consequentemente resolver os problemas emergentes de distribuição que surgiam, entre os anos 1902 e 1905, quatro acadêmicos, E. D. Jones, Simon Litman, George M. Fisk e W. E. Kreusi, nas universidades de Michigan, Califórnia, Illinois e Pensilvânia, começaram a oferecer cursos dentro das cadeiras de economia e administração para tratar dos assuntos emergentes relacionados aos processos de distribuição, e começaram a ensinar o que conhecemos atualmente como Marketing (ARANTES, 1975; BARTELS, 1951; JONES \& WITKOWSKI, 2008; LAZER, 1966; MAYNARD, 1941; MORE \& WILKIE, 2003).

Rev.Cad.Comun. Santa Maria, v.22, n.1, art 9, p.202 de 224, jan/abr.2018 
É o início de uma nova área de conhecimento para tratar, ou responder, as novas demandas do mercado. E assim, reflexo das mudanças sociais, econômicas e tecnológicas ocorridas no período, e pela procura em uma maior eficiência e lucratividade por parte das organizações, cria-se uma nova área de conhecimento e, por volta de 1910, o termo Marketing foi agregado aos já familiares "distribuição" e "intercâmbio"(BARTELS, 1976). Ou ainda a percepção de um dos primeiros autores da época, “(...) a palavra Marketing está entrando gradualmente em uso popular geralmente aplicado ao planejamento de distribuição" (BUTLER, 1914, p.12). É interessante destacar, na visão dos primeiros acadêmicos, o conceito de Marketing com foco na distribuição:

Marketing pode ser definido com o estudo dos princípios que governam as políticas de administração de negócios na distribuição de commodities do produtor ao consumidor. Isto inclui as atividades mercantis de varejo e atacado, organização das vendas das indústrias, e várias agencias engajadas na distribuição de matéria-prima, e todas as outras formas de facilitação e promoção de vendas de mercadorias (COPELAND, 1920, p.01,tradução nossa).

Esses estudos que tiveram como lócus a universidade, foram ofertados inicialmente dentro dos departamentos de economia, isso porque, surgem devido a uma lacuna, ou seja, pela constatação dos pesquisadores que as áreas que estudavam os sistemas de comércio no período de nossa pesquisa, como economia e administração, não possuíam em seu objeto de pesquisa os processos e as práticas de distribuição. Portanto essa investigações eram desenvolvidas nos departamentos de economia, porque os problemas de distribuição já haviam sido tratados nestes departamentos, mas não com a amplitude necessária. Assim, os cursos acabaram sendo oferecidos tanto por esses departamentos, quanto pelos de administração (BARTELS, 1976; MORE \& WILKIE, 2003).

As universidades de Wisconsin, Harvard, Minesota, Michigan State, Illinois e Ohio State estão entre os mais proeminentes centros de pesquisa e difusão de conhecimento norte-americano na primeira década do século passado, responsáveis por patrocinar as primeiras pesquisas e cursos, e contribuir para a institucionalização do Marketing como saber científico (ARANTES, 1975; BARTELS, 1951; JONES \& WITKOWSKI, 2008; LAZER, 1966; MAYNARD, 1941; MORE \& WILKIE, 2003).

Rev.Cad.Comun. Santa Maria, v.22, n.1, art 9, p.203 de 224, jan/abr.2018 
Esses centros de pesquisa também foram responsáveis pela formação de teóricos que propagaram os pressupostos desta nova área em outras universidades. Esta propagação de conhecimento para outras instituições de ensino ocorria na medida em que os pesquisadores mudavam de emprego para lecionar em outras escolas de negócio, e também quando criavam seus adeptos, aqueles alunos ou professores interessados em pesquisar o assunto de sua linha de pesquisa e serviam como propagadores deste novo conhecimento relacionado aos problemas de distribuição (BARTELS, 1976; OLIVEIRA, 2009).

Cada um desses grupos auxiliou na divulgação do conhecimento relacionado à nova área que surgia com pesquisas, artigos, congressos e outras formas usadas para a propagação de um novo campo de estudo, tais como cursos por correspondência e presenciais. Era um processo de divulgação que levara o aumento do número de pessoas interessadas em pesquisar os problemas relacionados aos processos de distribuição (BARTELS, 1968, OLIVEIRA, 2009). Para um melhor entendimento dessas contribuições, apresenta-se, á seguir, um quadro descritivo apresentando cada um dos centros de pesquisa.

\begin{tabular}{|c|c|c|}
\hline CENTRO DE PESQUISA & CONTRIBUIÇÃO & PESQUISADORES \\
\hline Grupo de Wisconsin & $\begin{array}{l}\text { Classificação e catalogação de } \\
\text { forma lógica e sistematizada dos } \\
\text { fenômenos da distribuição de } \\
\text { bens agricolas e manufaturados. } \\
\text { Concepção do campo como } \\
\text { "Marketing", e a oferta do } \\
\text { primeiro curso, Marketing } \\
\text { Cooperativo de Produtos } \\
\text { Agricolas }\end{array}$ & $\begin{array}{l}\text { Scott, Commons, Ely, Taylor, } \\
\text { Jones, Hagerty, Hibbard, } \\
\text { Macklin, Nystrom, Butler, } \\
\text { Converse, Comish e Vangham. }\end{array}$ \\
\hline Grupo de Harvard & $\begin{array}{l}\text { Produção de uma vasta } \\
\text { literatura, uma metodologia para } \\
\text { análise dos problemas de } \\
\text { distribuição, e o uso de casos } \\
\text { para ensinar Marketing }\end{array}$ & $\begin{array}{l}\text { Cherington, Shaw, Copeland, } \\
\text { Tosdal, Weidler, Maynard, } \\
\text { McNair, Borden e Vaile. }\end{array}$ \\
\hline $\begin{array}{l}\text { Grupo do Meio Oeste } \\
\text { (universidades de Minesota, } \\
\text { Michigan, Illinois e Ohio) }\end{array}$ & $\begin{array}{l}\text { Integração de conceitos, } \\
\text { enfatizando funções e principios } \\
\text { que caracterizam o corpo central } \\
\text { de sua literatura. }\end{array}$ & Weld, Ivey e Duncan. \\
\hline $\begin{array}{l}\text { Grupo de Nova York } \\
\text { (Universidade de Nova York e } \\
\text { Columbia) }\end{array}$ & $\begin{array}{l}\text { Análises institucionais de } \\
\text { Marketing. Catalisador dos } \\
\text { conceitos, teorias e ideias } \\
\text { propagadas pelos pesquisadores } \\
\text { dos demais centros }\end{array}$ & $\begin{array}{l}\text { Nystrom, Agnew, Brisco, } \\
\text { Wingate e Alexander. }\end{array}$ \\
\hline
\end{tabular}

Quadro 1 - Primeiros grupos de pesquisa para o estudo do Marketing Fonte: Adaptado pelos autores de Bartels, 1968 e Oliveira, 2009.

Rev.Cad.Comun. Santa Maria, v.22, n.1, art 9, p.200 de 224, jan/abr.2018 
Diante da discussão apresentada nota-se certa influência das ciências econômicas no nascente pensamento do Marketing. Dessa forma, nosso ensaio visa avançar no debate sobre a influência indireta que a filosofia e a metodologia cientifica do período contribuiu para o Marketing como campo científico, que florescera num período de produção em massa e marcado pela ênfase no escoamento da produção norte-americana. Realizamos uma pesquisa historiográfica pela produção acadêmica na primeira metade do século XX em Marketing para escrever este ensaio teórico.

Essa reflexão permeia a importância do processo de institucionalização do Marketing como campo científico, que no último século apresentou bases sólidas de difusão, ensino e pesquisa (OLIVEIRA, 2009), marcada pelas transformações dos centros urbanos norte-americanos (e.g. melhoria do transporte e oferta de trabalho) (MORE \& WILKIE, 2003). Essas mudanças criaram problemas no período industrial e, consequentemente, não podiam ser resolvidos por outras áreas do conhecimento tais como Administração (e.g. que se ocupara com assuntos do ambiente organizacional, preconizada pela Administração Científica de Taylor) e Economia (e.g. que se ocupara com assuntos de maior amplitude nas relações dos mercados e fatores de produção) (CONVERSE, 1945; OLIVEIRA, 2009; BARTELS, 1951A).

Para facilitar o entendimento, o ensaio está assim organizado. A próxima seção apresenta os tópicos referentes a influência do Positivismo de Comte nos estudos de Marketing e a relação entre o pensamento filosófico do período. A terceira seção apresenta a discussão em relação a cientificidade do Marketing, e encerra-se com as considerações finais.

\section{A FILOSOFIA, AS CIÊNCIAS E O MARKETING}

A corrente filosófica denominada de Positivismo, influente na primeira metade do século XX foi, segundo evidências apresentadas em nossa pesquisa, utilizada de forma implícita pelos intelectuais responsáveis pelos primeiros estudos em Marketing para torná-la uma área de estudo independente da Administração e da Economia, e para garantir sua importância científica no meio acadêmico. Isso devido ao fato que, como veremos à seguir, o uso de uma metodologia usada por outras áreas de conhecimento mas sedimentadas na academia poderia ser uma forma de garantir uma cientificidade de seus saberes, tanto na comunidade científica, como, em nosso caso em particular, no ambiente empresarial, e isso seria importante para o estabeleci-

Rev.Cad.Comun. Santa Maria, v.22, n.1, art 9, p.205 de 224, jan/abr.2018 
mento da área em seus primeiros anos de pesquisa (OLIVEIRA, 2009).

O Positivismo possuía como características filosóficas uma visão determinista e dos princípios de causalidade na concepção do universo, uma crença no progresso da humanidade que viria por meio das ciências naturais, ou seja, das ciências positivas, e dos avanços sociais que viriam em decorrência deste entendimento e controle de tais ciências (COMTE, 1978).

Cabe destacar que, como veremos adiante, nas primeiras obras publicadas em Marketing, como por exemplo a obra Marketing Methods de Butler, evidencia-se a busca por um método científico que validasse a importância da área, apresentando uma forte visão determinista, na qual, com o conhecimento das causas iniciais, os resultados finais poderiam ser facilmente determinados, ou seja, com o conhecimento dos agentes de distribuição, poder-se-ia determinar qual o resultado alcançado por uma determinada estratégia de Marketing.

Também que essas características ainda estão presentes no pensamento mercadológico atual, e ainda é tema de vários debates acerca do determinismo presente no pensamento mercadológico, como, por exemplo, os trabalhos de Diniz (2016), Hunt (1991), Oliveira (2017) e Thompson (1993). Porém, como o nosso objeto de pesquisa é analisar os primórdios do pensamento do Marketing, discutiremos apenas os pesquisadores desse período, não direcionando ao debate atual.

Á partir desse ponto concentraremos nosso ensaio para as características do Positivismo e sua relação com o pensamento mercadológico.

Iniciando com as características da filosofía positiva de Comte, é sua crença no progresso, baseado no caráter evolucionista do espírito humano, sendo analisado pela sua história. Para Comte (1978), para o entendimento da natureza e do caráter da filosofia Positiva, seria necessária uma visão geral sobre a marcha progressiva do espirito humano, que viria por meio do conhecimento de sua história. Ressaltam-se os aspectos progressistas do espírito humano, principalmente quando se analisa a sua história e percebe-se, na visão de Comte, as mudanças ocorridas nos saberes humanos em direção a um degrau maior do conhecimento da humanidade: "Nossa atividade intelectual estimula-se suficientemente com a pura esperança de descobrir as leis dos fenômenos, com o simples desejo de confirmar ou refutar uma teoria. Mas isto não poderia ocorrer na infância do espirito humano" (COMTE, 1978, p.25).

Infere-se o caráter evolucionista de sua filosofia, pois, segundo Comte

Rev.Cad.Comun. Santa Maria, v.22, n.1, art 9, p.206 de 224, jan/abr.2018 
(1978), a atividade intelectual de sua época se encontrava em um estágio mais avançado do pensamento intelectual da humanidade se considerar o início do pensamento intelectual do homem. Com isso, existiria um cenário propicio para melhor entendimento de sua filosofia que seria o ponto mais avançado deste conhecimento, deixando assim clara sua concepção de evolução e progresso da humanidade, seguindo sempre para um estágio superior do progresso e desenvolvimento.

Com essas características marcantes do Positivismo, no qual a sociedade passava por uma evolução em seus estágios, pode-se entender que foi responsável pelo otimismo dominante no início do século XX. Chaui (1999) destaca que a visão otimista que permeou o contexto teve como um importante nome o filósofo Augusto Comte, no qual atribuía o progresso ao desenvolvimento das ciências positivas, visto que permitiria aos seres humanos saber para prever, prever para saber de modo que o desenvolvimento social se faria pelo aumento do conhecimento cientifico da sociedade.

Desta forma tem-se uma visão otimista derivada na crença do progresso da humanidade via acúmulo de conhecimentos científicos e pelo controle das ciências naturais, ou das ciências positivas, em que tal controle daria a previsibilidade suficiente para garantir o progresso humano, permitindo assim "saber para prever e prever para saber" (CHAUI, 1999), e também, o desenvolvimento social que viria por meio do aumento e controle deste conhecimento científico. Abrão (2002) evidencia que movido pelo otimismo decorrente na crença do progresso tecnológico, o positivismo desenvolveu um considerável esforço para tomar o homem consciente de seu destino histórico, comprometido com a vocação tecnocientífica do mundo moderno. Para o autor, Comte representa a sobrevivência e afirmação iluminista adaptada à era industrial.

Quando investigamos os primeiros pesquisadores do período, é evidente a existência de uma visão prescritiva e determinista que, segundo nossas pesquisas, estava presente no pensamento da época. Na concepção determinista podemos também notar a noção de previsibilidade dos fenômenos, e para isso, Prigogine (2001) salienta que de um lado existia as leis da natureza, das quais as leis de Newton (aceleração proporcional à força) era o mais importante exemplo do período. Essas leis (que hoje incluem a mecânica Quântica e a Relatividade) têm dois aspectos gerais norteadores de seus preceitos, são determinísticas (se você souber as condições iniciais, tanto o futuro como o passado podem ser determinados) e reversíveis no tempo,

Rev.Cad.Comun. Santa Maria, v.22, n.1, art 9, p.207 de 224, jan/abr.2018 
por isso, a ciência era associada à certeza.

Essa visão de previsibilidade dos fenômenos estava presente no pensamento das ciências no início do século passado, "no início deste século [XX] prevalecia uma visão determinista das leis da natureza. Os físicos estavam então preocupados com as noções e princípios da estabilidade, de equilíbrio " (PRIGOGINE, 2001, p.37). Para o pensamento do período, e influenciando a visão dos pesquisadores de Marketing, com o conhecimento do que poderia acontecer no mercado, permitir-se-ia uma maior previsibilidade e a construção de normas e procedimentos para as estratégias mercadológicas, ou seja, no modo de tratar os assuntos de distribuição.

Os teóricos do período, conforme nossas pesquisas indicam, acreditavam que com o conhecimento dos dados do mercado, das empresas envolvidas no setor, e dos hábitos dos consumidores, os resultados das estratégias de Marketing poderiam ser determinados, ou seja, se todo o planejamento fosse realizado conforme prescrito nas obras do período, os resultados seriam determinados com certa previsibilidade.

Em relação ao determinismo presente na literatura do Marketing, Bartels (1976) menciona que a teoria mais familiar aos estudantes da época seria o determinismo econômico, no qual a evolução de uma ordem mercadológica é atribuída ao desenvolvimento econômico. Para o autor, a sociedade tinha progredido, através de etapas de saque, caça, pastoreio, agricultura, artesanato, indústria e, finalmente, o Marketing, que estaria associado com a etapa de abundância econômica que dava mais importância à distribuiç̧ão, à inovação de produtos para o consumidor, o serviço, etc. Assim se explica segundo o determinismo econômico, o surgimento do Marketing em nossa época. É a influência do determinismo econômico como uma forma de pensar os agentes envolvidos no processo do Marketing. Para os pensadores do período é uma ideia de evolução das práticas mercantis que partiam para estágios superiores, e que o Marketing seria o ponto mais elevado nesse processo de aparente evolução.

Ainda em relação ao determinismo, tem-se, para os teóricos, uma forma de pensar e ensinar o Marketing como um "livro de receitas", visto que acreditavam que, quando um praticante de Marketing estivesse com a necessidade de um conselho relativo ao Marketing de um produto, poderia simplesmente encontrar em qual categoria se encontrava, e então seguir a receita prescrita para aquela categoria (SHETH, GARDNER E GARRET, 1988).

Aparentemente, bastaria classificar os produtos em uma categoria pre-

Rev.Cad.Comun. Santa Maria, v.22, n.1, art 9, p.208 de 224, jan/abr.2018 
determinada para encontrar uma solução com certa previsibilidade para cada uma das situações que eram apresentadas. Sheth et al. (1988) ainda ressalta que os teóricos da commodity (primeira escola do pensamento do Marketing) estavam entusiasmados com a possibilidade de criar um "livro de receitas em Marketing" tendo como base em um sistema de classificação. Isso poderia ser benéfico aos praticantes da área que pareciam estar mais interessados em assuntos relacionados ao 'como fazer' do que "porque é feito".

Parece-nos que, segundo evidências apresentadas por Sheth, os intelectuais da área se apoiaram no pensamento filosófico e científico do período com relação aos preceitos de causa e efeito e a consequente previsibilidade dos fenômenos mercantis. Uma visão relacionada ao "fazer" e não aos motivos pelos quais essas ações ou estratégias deveriam ser realizadas. Com essa previsibilidade poderiam prescrever as melhores estratégias que seriam usadas pelos praticantes de Marketing, e assim, com um método estruturado e com base em uma metodologia científica apropriada, poderiam atingir o mesmo status das ciências da época.

Portanto, a filosofia positivista que permeou a visão dos pensadores no período que coincidiu com os primeiros estudos em Marketing consistia basicamente em elaborar formas lógicas e racionais de estabelecer e determinar leis para os fenômenos da natureza através das ferramentas da catalogação de forma enciclopédica dos conhecimentos científicos, conhecimentos estes mencionados pelas diversas ciências existentes, de uma forma hierárquica de subordinação dos saberes. Tal técnica facilitaria não apenas a relação de interdependência entre estas ciências, mas também a compreensão do conhecimento da humanidade, sempre de maneira lógica e racional.

O objetivo principal de Comte (1978) era estabelecer uma filosofia que atuasse como o coordenador de um sistema lógico, racional e geral de conhecimento científico, haja vista que as ciências, como ele mencionava ciências positivas, se encontravam em suas grandes linhas já delimitadas e organizadas racionalmente, e este sistema organizacional seria construído através de uma classificação e ordenação dos conhecimentos científicos, e consequentemente sua possível utilização por parte da sociedade, assim facilitaria o seu desenvolvimento e progresso e traria o bem geral da humanidade. Comte (1978) iniciou seu trabalho enumerando os três estágios pelos quais passa o conhecimento da humanidade, que seriam o Teológico

Rev.Cad.Comun. Santa Maria, v.22, n.1, art 9, p.209 de 224, jan/abr.2018 
(fictício para o autor), o Metafisico (abstrato para o autor) e o Positivista (científico para o autor), este último seria o estado mais avançado do pensamento científico.

Esta noção de desenvolvimento e progresso pode ser notada nos estudos de Marketing, no qual as transações mercantis evoluíram dos antigos saques, passando pelos estágios de pastoreio, agricultura, artesanato, indústria até chegar ao Marketing, que era o estágio mais avançado nos processos de comercialização (BARTELS, 1974) que, tal como Comte (1978) estabeleceu o conhecimento científico passando por várias fases em sua evolução, sendo o estado positivo o mais evoluído neste processo.

Essa evolução também é mencionada por Kotler (1996), na qual as divide em "eras" pelas quais as empresas passaram no decorrer de sua história. Era da Produção (1900-1930) na qual o foco das empresas era escoar a produção em massa das empresas que cresciam em termos de tamanho, quantidade produzida e abordagem de mercado. Facilitadas pelos desenvolvimentos em termos produtivos e, com um mercado ávido pelos produtos que começaram a ser disponibilizados pelas empresas. A única preocupação por parte das organizações era disponibilizar os seus produtos ao mercado, sem preocupação com as necessidades de seus consumidores (KOTLER, 2012; COBRA, 1992; OLIVEIRA, 2007).

Era das Vendas (1930-1950) onde as organizações pensavam apenas em estratégias de promoção e vendas. Ao contrário do período anterior, a oferta supera a demanda. Os estoques aumentam devido à melhoria da capacidade de produção das fábricas impulsionados pelas novas técnicas de produção, pelo uso de novas tecnologias, e por técnicas mais adequadas de organizar e administrar essas empresas. O Marketing, passa, então, a enfatizar as práticas e estratégias de vendas, pois os pesquisadores de mercado acreditavam que os consumidores não comprariam seus produtos se não existisse um esforço substancial em sua promoção. (KOTLER, 2012; COBRA, 1992; OLIVEIRA, 2007).

Era do Marketing (à partir de 1950) na qual a filosofia das empresas passou a ser centrada na satisfação das necessidades e desejos dos consumidores. No final da década de 1940 e início da década de 1950, novamente, devido a mudanças no contexto organizacional e social, e com o fortalecimento de outras áreas que aplicavam os seus estudos dentro das organizações, nos quais os pesquisadores mercadológicos emprestaram conceitos, surge o conceito atual de Marketing. Os teóricos perceberam

Rev.Cad.Comun. Santa Maria, v.22, n.1, art 9, p.210 de 224, jan/abr.2018 
que as vendas a qualquer custo, característica do relacionamento anterior das empresas com o mercado, não era a forma mais eficaz de manter a fidelidade dos clientes. Assim, subsidiado pelos estudos em Psicologia aplicados à Administração e as Teorias da Comunicação, que permitiam melhor entendimento dos clientes, surge o conceito atual de Marketing, com o objetivo de satisfazer as necessidades e desejos dos consumidores (KOTLER, 2012; COBRA, 1992; OLIVEIRA, 2007).

Também pode-se notar essa perspectiva evolucionista do Marketing pela visão de Bartles (1974) : 1. Marketing preocupado com a distribuição e venda, que compreende o período de seu surgimento, 1900 até aproximadamente 1920. Nessa abordagem do pensamento mercadológico, sua ênfase era nas funções técnicas dos agentes de distribuição; 2. Marketing como um empreendimento distributivo - com início em 1920, teve como ênfase os agentes de distribuição, ou seja, as empresas distribuidoras. $O$ objetivo do Marketing é centrado no gerenciamento dos distribuidores; 3. Marketing como gerenciador do processo de distribuição, demarcado durante a década de 1950. O pensamento do Marketing atua sobre as variáveis mercadológicas conhecidas como os 4 ps ou Marketing Mix, "Produto, Preço, Praça e Promoção", que passam a representar o Marketing Concept; 4. Marketing como tomada de decisão gerencial, ainda na década de 1950, com a introdução de novos conceitos gerenciais para o pensamento do Marketing; 5. Marketing como um processo social, no qual é delimitado como final da década de 1950, na qual a ênfase passa a ser o aspecto humanístico do Marketing e aumento do escopo de atuação, abrangendo instituições não empresariais; 6 . Marketing como um processo social, demarcado com a década de 1960, no qual o Marketing é visto não apenas como um processo social envolvendo participantes econômicos, mas como um processo societário, sendo visto como um agente dentro da estrutura social de um determinado grupo; 7. Marketing como uma função gerencial aplicável a instituições empresariais e não empresarial, no final dos anos 1960.

Também podemos pensar no campo do Marketing, com a sua evolução, ou transformação conceitual com visão de More \& Wilkie (2003), no qual existiu o . Pré-Marketing" (antes de 1900): Não havia um campo de estudo distinto, e os assuntos eram tratados dentro do campo da economia; I. "Fundação do Campo" (1900 - 1920): Desenvolvimento dos primeiros cursos, ênfase nas atividades de Marketing dentro da instituição econô-

Rev.Cad.Comun. Santa Maria, v.22, n.1, art 9, p.211 de 224, jan/abr.2018 
mica, e foco na distribuição; II. "Formalizando o Campo" (1920 - 1950) : Desenvolvimento dos fundamentos aceitos como "princípios de marketing", estabelecimento da infraestrutura de desenvolvimento do conhecimento para o campo como a criação da associação profissional (AMA), conferências, journals (Journal of Retailing e Journal of Marketing); III. "Uma Mudança de Paradigma - Marketing, Gerenciamento, e as Ciências" (1950 - 1980) : Explosão do crescimento nos EUA do mercado de massa e do corpo de pensamento, e duas perspectivas começam a dominar o pensamento da área: (1) a visão gerencial e (2) as ciências comportamentais e quantitativas como chaves para o desenvolvimento futuro do conhecimento. Nesse momento, a infraestrutura do conhecimento passa por sua maior expansão e evolução; IV. "A Mudança se Intensifica - Uma Fragmentação do Mainstream" (1980 - presente): Novos desafios surgem no mundo dos negócios: foco financeiro no curto prazo, downsizing, globalização e reengenharia. Também destaca-se que as perspectivas dominantes são questionadas nos debates da filosofia da ciência. "Publicar ou Perecer" é a pressão por publicação que se intensifica na academia. Infraestrutura do conhecimento expande e diversifica em áreas de interesse especializado.

Sob outro olhar em relação a forma pela qual os pesquisadores encaram o processo de evolução da área, mas, principalmente, em sua busca, como disciplina acadêmica, temos a "evolução" e prática do Marketing conforme Lusch (2007) no qual afirma que a disciplina caminhou por três estágios, nos últimos cem anos: 1) “To marketing”: o objetivo principal do marketing é trazer coisas ao mercado, isso porque o comprador e o vendedor estão separados no mercado. Oferta e capacidade produtiva são escassos, e assim, o papel do Marketing é alocar esses recursos escassos; 2) "Market (ing) to": a missão principal do marketing é identificar clientes e realizar o marketing para eles, isso porque, como os setores industrial e de distribuição da economia tornaram-se mais desenvolvidos, o que surgiu não era uma falta de abastecimento e sua distribuição eficiente, mas sim uma falta de clientes e mercados. Portanto, as organizações necessitavam encontrar clientes para os seus produtos, isso significa que deveriam ser orientadas para o cliente. 3)“Market (ing) with”: seria o estágio mais avançado, no qual seriam empresas que tem como filosofia enxergar o cliente como endógeno e como um parceiro na co-criação. Seria um estágio mais avançado do relacionamento e pensamento do Marketing, e já estaria sendo praticado por um número crescente de empresas inovadoras.

Rev.Cad.Comun. Santa Maria, v.22, n.1, art 9, p.212 de 224, jan/abr.2018 
Logo, a pesquisa apresenta indícios que a área de Marketing se apoiou na filosofia de Comte (1978), com relação ao caráter evolutivo das ciências em busca de um patamar mais avançado do conhecimento humano para subsidiar esta área do saber como uma disciplina independente da Administração e Economia, ou seja, assim como as ciências tradicionais, o Marketing possui um campo de estudo que passa por transformações evolutivas nos mesmos moldes das ciências tradicionais. E um aspecto importante, esse visão "evolucionista” ainda está presente na concepção de atuais pesquisadores, como presenciamos no teóricos citados.

A busca dos pesquisadores do Marketing por uma legitimidade científica com a utilização de métodos comtinianos pode ser verificada com mais uma das características presentes em sua filosofia, na qual destacamos a divisão dos saberes:

Por uma lei cuja necessidade é evidente, cada ramo do sistema cientifico se separa insensivelmente do tronco, desde que cresça suficientemente para comportar uma cultura isolada, isto é, quando chega a ponto de poder ser a ocupação exclusiva da atividade permanente de algumas inteligências. É a essa repartição de diversas espécies de pesquisa entre diferentes ordens de sábio que devemos, evidentemente, o desenvolvimento tão notável que tomou, enfim, em nossos dias, cada classe distinta dos conhecimentos humanos e que torna manifesta a impossibilidade, entre os modernos, dessa universalidade de pesquisas especiais, tão fácil e tão comum nos tempos antigos. Numa palavra, a divisão do trabalho intelectual, aperfeiçoada progressivamente, é um dos atributos mais importantes da filosofia positiva. (COMTE, 1978, p. 31)

Essa mesma busca por uma divisão dos saberes pode ser notada no pensamento do Marketing evidenciados nas palavras de Bartels (1951b), no qual descreve que durante o período de 1910-1920, três posicionamentos de analise mercadológica foram formulados: por mercadorias, por instituições e o funcional, sendo que o primeiro era um estudo dos processos compreendidos no Marketing de um produto ou grupo de produtos. O segundo uma análise descritiva das instituições de atacado e varejo. E, o terceiro um estudo das funções e analise de Marketing. Isto é, uma busca pela divisão dos conhecimentos para melhor estudo e compreensão das atividades ligadas a distribuição de bens e serviços. Com esta divisão tentou-se estabelecer uma classificação lógica e homogênea para uma poste-

Rev.Cad.Comun. Santa Maria, v.22, n.1, art 9, p.213 de 224, jan/abr.2018 
rior generalização dos fenômenos atribuídos as práticas de distribuição e comercialização por parte das organizações para o consequente estabelecimento de leis que poderiam reger as relações entre os agentes envolvidos nas transações comerciais (SHETH et al. 1988).

Também se destaca a hierarquização, se assim pode-se dizer dos fenômenos, funções e analise de Marketing por se tratar das atividades relacionadas ao desempenho da organização como um todo e suas relações e inter-relações com o ambiente onde estaria inserida, a classificação dos produtos comercializados pelas organizações. Em relação a hierarquização dos conhecimentos podemos notar que foi também uma característica da filosofia continiana, evidenciado em Abrão (2002), no qual a hierarquização comtiniana das ciências obedecia a princípios de cronologia, complexidade, generalidade e dependência. Portanto, as ciências mais gerais, mais abstratas e mais autônomas do ponto de vista metodológico ocupariam os primeiros lugares em uma escala de saber. As mais concretas, menos gerais e metodologicamente mais dependentes de outras ocupariam as últimas posições. Essa hierarquização formaria uma cadeia, e para Comte, no topo estaria a astronomia e que termina com a sociologia ou a física social para a sua filosofia.

A influência de Comte (1978) e sua filosofia positivista no Marketing é verificada na ênfase na catalogação dos saberes da literatura mercadológica, e principalmente, como uma forma de demonstrar que esta área de estudo poderia ser importante no meio acadêmico e empresarial e deveria ser uma área de estudo independente das áreas mais desenvolvidas (SHETH et al. 1988), pois seguiria os mesmos critérios metodológicos presentes nas ciências da época, mais precisamente, a catalogação de seus agentes e funções.

Apenas para exemplificar esta busca de catalogação dos produtos em relação aos mercados e com isso avalizar a importância do Positivismo nas escolas de mercadologia, Sheth et al. (1988) mencionam que no ano de 1912 os produtos foram catalogados como Bens de Conveniência e de Emergência, em 1923 como Bens de Conveniência, Bens de Compra e de Especialidade, entre outros catalogados. Ou seja, a busca de uma catalogação dos produtos, que era o objeto de estudo do Marketing na primeira metade do século XX para uma posterior generalização ou estabelecimento de leis, para com isso facilitar as estratégias a serem utilizadas pelas organizações.

Rev.Cad.Comun. Santa Maria, v.22, n.1, art 9, p.214 de 224, jan/abr.2018 
Com esta classificação e catalogação a mercadologia poderia ganhar um status científico no meio acadêmico, pois seria um ramo de estudo que possuía leis para fenômenos homogêneos que aconteciam nas transações comerciais e tentar garantir a sua importância como uma área de conhecimento independente. Haja vista que possuía um objeto de estudo delimitado, poderia ser classificado de uma forma lógica e propunha a generalização dos fenômenos.

Graças a esta classificação Sheth et al. (1988) mencionam que quando os estudantes de Marketing encontrassem algum problema de mercado, bastaria verificar em qual categoria este produto se encontrava, com a finalidade de identificar as melhores soluções e estratégias para as situações que envolviam tais produtos. As soluções estavam pautadas em técnicas de mercado, formas de distribuição (densidade), métodos de distribuição (atacadistas) e as relações com o comerciante. Para o autor e os pesquisadores do período, um dos objetivos da área que surgia era a criação de um "Livro de Receitas" que poderiam ser consultados quando um problema de distribuição assim surgisse. Ao que parece, seria uma visão determinista dos fenômenos de distribuição que surgiam no mercado norte-americano.

Para um melhor entendimento dos preceitos filosóficos e científicos dos primeiros pensadores em Marketing, nos deteremos, nessa parte do ensaio, a obra Marketing Methods publicada em 1914, sendo o seu autor, Ralph S. Butler, considerado, segundo Bartels (1974) e Weld (1941) como o responsável por nomear a área que surgia como Marketing.

Marketing Methods é dividida em três partes ordenadas metodologicamente por uma hierarquia de importância em relação a forma do autor pensar os problemas emergentes de distribuição que eram apresentadas no contexto empresarial norte-americano. Ele procurou abordar temas que seriam, ao menos para o período, os mais importantes para as organizações. Assim trata dos conhecimentos de Marketing conhecido como o planejamento da distribuição, publicidade (de uma forma mais simplificada quando trata de assuntos relacionados ao plano de campanha) e vendas. É o que notamos em Comte sobre a sua hierarquia e divisão dos saberes para um melhor entendimento dos fenômenos pesquisados, e consequentemente para o estabelecimento de leis e regras para os problemas de distribuição, ou para a nascente área de Marketing (BUTLER, 1914).

Primeiramente percebe-se que a obra Marketing Methods desenvolvida para as suas aulas na University of Wisconsin é baseada em uma observa- 
ção sistemática dos problemas que ocorriam nos processos de comercialização existentes no período. Butler, em sua experiência como executivo da área comercial de uma grande corporação norte-americana permitiu uma visão mais completa do mercado, de seu relacionamento com os consumidores e dos problemas que ocorriam nesse processo mercantil. Em sua carreira empresarial foi assistente do diretor de vendas para o oeste da Procter \& Gamble Company, seu primeiro trabalho no campo do Marketing. Nessa fase de sua careira ficou impressionado com o fato de que as empresas, mais precisamente aquelas relacionadas a produtos manufaturados, tinham que considerar um grande número de problemas antes de aplicar as suas estratégias de vendas e publicidade (WELD, 1941).

Esta observação sistematizada dos processos de distribuição permitiria uma descrição do que ocorria no mercado e, com esta descrição levaria a definições, conceitos e normas para estes processos. Também com este conhecimento do mercado facilitaria uma maior previsão dos fenômenos que poderiam ocorrer no mercado em relação a distribuição e comercialização dos produtos em seus respectivos mercados.

Repara-se o caráter descritivo e prescritivo da obra de Butler (1914) na parte II - Vendas. Onde cabe destacar, entre outros aspectos, os passos preliminares de uma entrevista de vendas: a entrevista propriamente dita, como fechar um acordo comercial e também quais as qualificações necessárias para se tomar um bom vendedor. Na parte III - Administração de Vendas, têm-se a explicação do que é administração, as formas mais adequadas de selecionar e treinar os vendedores e os principais métodos de venda. Bastava aos primeiros estudantes da área seguir as suas instruções para que as vendas fossem substanciais.

O caráter de "Livro de Receitas" como alguns pesquisadores costumam descrever este processo também pode ser constatado após a sua observação metódica dos processos mercantis. Butler (1914) procurara descrever os fatos e prescrever as melhores formas de relacionamento com o mercado, ou seja, o autor pensara em um texto que seria mais adequado para o ensino das estratégias de distribuição. 


\section{A "CIENTIFICIDADE" DO MARKETING}

A cientificidade do Marketing, ou a procura por indícios que sustentem a posição da área sempre esteve presente no debate dos acadêmicos. Pode-se entender a ciência como o conjunto de conhecimentos de uma determinada área de estudos, conhecimentos estes adquiridos de forma ordenada e sistematizada, baseado em princípios, argumentações ou demonstrações que servem para estabelecer princípios e leis que podem ser generalizadas para outros eventos da mesma natureza (KUHN, 2006). São essas características que foram colocadas em debates nos primeiros anos do processo de institucionalização do Marketing nos Estados Unidos nas primeiras décadas do século $X X$.

Em relação a esse debate, é interessante nesse momento mencionar um importante artigo publicado por Bartels em 1951, Can Marketing be a Science?. De acordo Bartels (1951a) o motivo do Marketing não ser caracterizado como uma ciência seria resultado de dois fatores. Primeiro, o objetivo da ciência não é sempre encontrado no estudo desta área. Segundo, ainda que sua meta da investigação, normalmente, é o estudo dos fenômenos de mercado de modo científico, isto não tem sido o objetivo dos profissionais desta área para estabelecer uma ciência no Marketing.

Com relação ao objeto de estudo desta área, pode-se entender que por se tratar do estudo de transações comerciais entre empresa e consumidor, e por não ser fenômenos ligados a natureza, seu objeto de estudos invalidaria suas conotações científicas. Apesar de que, como mencionado pelo Positivismo de Comte, ele demonstrara certa preocupação com os estudos relacionados as indústrias, onde destaca a importância dos engenheiros e suas aplicações práticas das ciências (COMTE, 1978), ainda existia certa desconfiança com o objeto de estudo do Marketing. Cabe destacar que essa é uma visão da década de 1950.

Tendo como base de discussão o objetivo das ciências, que não são encontradas nos profissionais e pensadores desta área, pode-se ressaltar a procura de verdades gerais para construção de leis e princípios que seriam derivados de uma classificação e catalogação dos fenômenos de forma sistematizada e organizada, como eram as práticas normais de investigação científica no período, para a formação de um campo de estudos que proporcionariam o debate, a crítica e a investigação destas e outras verdades, proporcionando assim certo grau de progresso desta área, colocando-a,

Rev.Cad.Comun. Santa Maria, v.22, n.1, art 9, p.217 de 224, jan/abr.2018 
desta forma, em um padrão de ciência, o que mais uma vez é enfatizado na busca por uma padronização dos fenômenos ligados aos processos de distribuição e, uma forte conotação determinista e de causalidade.

Para Bartels (1951b), o Marketing, como uma ciência consiste de um corpo conhecimentos de distribuição de bens e serviços com uma metodologia, teoria, princípios e conceitos próprios para sua área de atuação. $\mathrm{O}$ autor enumera os fatores pelos quais esta área de conhecimento pode ser considerada uma ciência. Primeiro, o objeto de observação e investigação pode ser estabelecido por leis gerais e amplos princípios, não meramente determinadas em procedimentos operacionais. Segundo, as predições feitas pelo desenvolvimento de leis poderiam ser de importância social e não meramente uma aplicação institucional. Terceiro, teorias e hipóteses empregadas nas predições e no esboço para facilitar as inferências poderiam ser úteis para extensão do conhecimento como bem para guiar formas administrativas em tomo de fins lucrativos. Quarto, abstrações assim como fatos concretos poderiam ser usados na explanação de fenômenos de Marketing.

Pelas ideias de Bartels (1951b) esta área de conhecimento pode ser considerada uma ciência, pois, o seu objeto de investigação e observações serviriam para o estabelecimento de leis e princípios, com certo poder de generalização de fenômenos. Um dos pontos importantes para que uma área de conhecimento possa ser conhecida como ciência, é necessária em sua literatura a presença de elementos da metodologia científica como a observação, uma terminologia, classificação, experimentação e analise, o que, para o autor, existe no corpo de conhecimento do Marketing, e em nossa análise, também presenciamos partes desses pressupostos metodológicos.

Em relação a observação, na qual acredita-se ser uma das mais importantes características do Marketing, e presente como características das ciências da época, Bartels (1951b) destaca que alguns estudos de mercadologia da primeira metade do século XX foram baseados na observação, por professores pioneiros na área. Devido ao fato de não estarem familiarizados com as atividades de distribuição, recorriam em primeira mão à observação para falar ou escrever sobre o assunto. Os professores acompanhavam commodities no mercado em ordem de seu trajeto, para observar onde era o seu início, e como e por quem ele era manuseado. Eles falavam com comerciantes e observavam o comportamento do consumidor como

Rev.Cad.Comun. Santa Maria, v.22, n.1, art 9, p.218 de 224, jan/abr.2018 
também da distribuição. Os pesquisadores observavam, acompanhavam e conversavam com comerciantes para entender seus problemas de distribuição e propunham soluções que auxiliariam este processo, com isso, este importante aspecto metodológico esteve sempre presente na literatura desta área.

Outro importante aspecto metodológico destacado por Bartels (1951b) é a classificação dos dados, que facilitaria a formulação de leis científicas. Entre os numerosos fenômenos classificados destacam-se: tipos de consumidores, mercados, estabelecimentos de atacado e varejo, funções de Marketing, motivos de compra, commodities e serviços, canais de distribuição, políticas e práticas.

As predições feitas com o desenvolvimento de leis poderiam possuir uma aplicação maior, não sendo destinadas apenas as práticas mercantis, e sim, também a relacionamentos sociais. Acredita-se que esta amplitude de atuação na qual Bartels (1951b) se refere pode ser nos dias atuais um dos principais motivos pelos quais o Marketing sofra críticas. E, ainda tenha dificuldade para se estabelecer no meio acadêmico. Pois, quanto maior sua aplicação maior serão as dificuldades de encontrar especialistas que se dedicam ao estudo.

\section{CONSIDERAÇÕES}

Este ensaio teórico teve como objeto de estudo a sistematização e organização do conhecimento do Marketing no início do século XX, e como objetivo avançar na discussão sobre a influência da filosofia e das ciências nos primeiros estudos da área, que florescera num período de produção em massa e marcado pela ênfase no escoamento da produção norte-americana. Realizamos uma pesquisa historiográfica pela produção acadêmica na primeira metade do século XX em Marketing para escrever esse ensaio.

Constatamos que os primeiros pesquisadores da época possuíam em sua visão dos sistemas de distribuição a noção de evolução e progresso que incentivara os acadêmicos a estudar os problemas de comércio e distribuição, por acreditarem que a área, bem como os processos de distribuição e industrialização passavam por avanços consideráveis. Pois, a humanidade estava em um processo de progresso passando para um estágio mais avançado do que era apresentado no momento, os consumidores e consequentemente as organizações também participavam desse proces-

Rev.Cad.Comun. Santa Maria, v.22, n.1, art 9, p.219 de 224, jan/abr.2018 
so, teoricamente, evolucionista. Os consumidores, cientes ou não deste progresso, atuavam de maneira lógica (para o pensamento dos autores da época isso significa que seriam facilmente determinados) e, assim, poderiam determinar as suas ações e o seu pensamento com o uso de técnicas e um planejamento dos fenômenos de distribuição.

Esta evolução progressista da sociedade e do mundo como um todo pode ser facilmente percebida quando eram presenciados os avanços tecnológicos derivados da $2^{\mathrm{a}}$. revolução industrial que forneceram recursos para o crescimento das empresas e a consequente melhoria no padrão de vida dos habitantes dos Estados Unidos e ajudava a validar esta concepção otimista em relação ao progresso destes agentes. Este cenário teoricamente em evolução no contexto organizacional garantiria um amplo campo para os estudos em distribuição, pois as empresas tenderiam a evoluir e crescer em tamanho e complexidade. Esse crescimento acarretaria a necessidade de melhores formas de relacionamento entre as empresas e seus consumidores. Abrindo possibilidades ilimitadas para as empresas com a venda de seus produtos e os consumidores com uma melhor qualidade de vida fruto deste relacionamento com essas organizações. E, assim poderia abrir um campo para um novo especialista de mercado, os especialistas em Marketing.

Identificamos que os primeiros estudos em Marketing possuíam em suas bases metodológicas muitas das características do Positivismo de Augusto Comte, como a divisão e hierarquização dos fenômenos de distribuição e os preceitos de causalidade para que assim pudesse garantir um staus cientifico para área e uma independências de outras áreas mais sedimentadas como a Economia e Administração de empresas.

Verificamos que desde a década de 1950 os pesquisadores do período, tendo como base o processo de institucionalização do Marketing discutiam a cientificidade da área, usando sempre como base de comparação as ciências e o pensamento filosófico do período, mais precisamente o Positivismo de Augusto Comte.

Esperamos que esse ensaio possa contribuir para o debate do ensino do Marketing, isso devido ao fato de nossa crença que entender as origens de uma área de conhecimento, e o método, baseado na filosofia e nas ciências, para verificar como os primeiros pesquisadores tratavam o pensamento do Marketing, proporciona diferentes interpretações em relação a sua história, auxilia o entendimento do processo de criação de conceitos,

Rev.Cad.Comun. Santa Maria, v.22, n.1, art 9, p.220 de 224, jan/abr.2018 
ferramentas e estratégias, e o principal, contribuí em seu estabelecimento como disciplina, uma disciplina ou área de conhecimento com história, e alicerces que sustentam suas bases, suas origens e sua trajetória.

\section{REFERÊNCIAS}

ABRÃO, B. S. História da Filosofia. São Paulo: Best Seller, 2002.

AJZENTAL, A. Uma história do pensamento em marketing. Tese de Doutorado.São Paulo: Universidade Getúlio Vargas - FGV, 2008.

AMA-American Marketing Association. (2016). Disponivel em: <https://www.ama.org/ AboutAMA/Pages/Definition-of-Marketing.aspx>. Acesso em: 19 Dezembro 2016.

ANDERSON, J., NARUS, J. A. Model of Distribuitor Firm and Manufacturer Firm Working Partnerships. Journal of Marketing, 54 (1), 42-58, 1990.

ARANTES, A. C. A. Administração Mercadológica. Rio de Janeiro: Fundação Getúlio Vargas, 1975 .

BARTELS, R. Can Marketing be a Science? Journal of Marketing, 15 (2), 319-328, 1951 (a).

. Influences on the Development of Marketing Trought 1900-1923. Journal of Marketing, 16 (3), 1-17, 1951 (b).

. Sociologists and Marketologists. Journal of Marketing, 25(4), 37-40, 1960.

. The General Theory of Marketing. Journal of Marketing, 32(1), 29-33, 1968.

. The Identify Crisis in Marketing. Journal of Marketing, 38 (3), 73-76, 1974.

. The History of Marketing. Ohio: Grid, 1976.

BAUMOL, W. J. On Role of Marketing Theory. Journal of Marketing, 23(1), 413-418.

BUTLER, R. S. Marketing Methods. New York: Alexander Hamilton Institute, 1914.

CHAUI, M. Convite a Filosofia. São Paulo: Ática, 1999.

Rev.Cad.Comun. Santa Maria, v.22, n.1, art 9, p.221 de 224, jan/abr.2018 
CADERNOS DE COMUNICAÇÃO

UNIVERSIDADE FEDERAL DE SANTA MARIA

CHERRINGTON, P. T. Elements of Marketing. Nova York: The Macmillan Company, 1921.

COBRA, M. Administração de Marketing. São Paulo: Atlas, 1992.

COMTE, A. Curso de Filosofia Positiva. São Paulo: Abril Cultural, 1978.

CONVERSE, P. D. The Development of Science Marketing-An Exploratory Survey. Journal of Marketing, 7 (1), 14-23, 1945.

COPELAND, M. T. Marketing Problems. Nova York: Shaw Company, 1920.

DINIZ, A. P. C. Marketing Critico: precisamos falar sobre isso. VII Encontro de Marketing da ANPAD. Belo Horizonte: [s.n.]. p. 1-18, 2016.

GRISI, C. C. H.; GRISI, J. R. M.; SANTOS, R. C. Marketing: As Controvérsias do Marketing Moderno. Revista de Administração, v. 18, n. 4, p. 59-65, 1983.

HOBSBAWM, E. J. A Era dos Impérios. Rio de Janeiro: Paz e Terra, 2002.

HUNT, S. D. Positivism and paradigm dominance in consumer research: toward critical pluralism and rapprochement. Journal of Consumer Research, v. 18, n. 1, p. 32-44, 1991.

JONES, D. G. B., E T. H. WITKOWSKI. Historiography in Marketing: Its Growth, Structure of Inquiry, and Disciplinary Status. Business History Conference, 2008.

KOTLER, P. Marketing - Edição Compacta. São Paulo: Atlas, 1996.

KOTLER, P; KELLER, K. L. Administração de Marketing. São Paulo: Pearson, 2012.

KUHN, T. M. A Estrutura das Revoluções Científicas. 9. Ed. São Paulo: Perspectiva, 2006.

LAS CASAS, A. L. Marketing - Conceitos, Exercícios e Casos. São Paulo: Atlas, 2001.

LAZER, W. Interdisciplinary Horizons in Marketing. Journal of Marketing, 25 (Out), 2430, 1960.

LITTLE, R. W. The Marketing Channel: Who Should Lead this Extra Corporate Organization. Journal of Marketing, 34 (1), 31-38, 1970.

Rev.Cad.Comun. Santa Maria, v.22, n.1, art 9, p.222 de 224, jan/abr.2018 
MAYNARD, H. H. Early Teachers of Marketing. Journal of Marketing, (Out.), 158-159, 1942.

MELANDRI, P. A. A História dos Estados Unidos desde 1865. Lisboa: Edições 70, 2001.

OLIVEIRA, S. L. I. Desmistificando o Marketing. São Paulo: Novatec, 2007.

.The Firsts studies in Marketing: context, institutionalization and method. $\overline{2009.179} \mathrm{f}$. Thesis (PhD in History of Science). Pontifícia Universidade de São Paulo-PUC/SP, São Paulo, 2009.

OLIVEIRA, S. L. I.; MORETTI, S. L. A.; SILVA, L. A. Os Primeiros Estudos em Marketing: A Influência da Filosofia e das Ciências nos Primeiros Estudos em Marketing-Uma Análise da Obra Marketing Problems de Melvin T. Copeland. Revista Brasileira de Marketing. e-ISSN: 2177-5184, v. 16, n. 4, 2017.

PIERANTI, O. P. A metodologia historiográfica na pesquisa em administração: uma discussão acerca dos princípios e sua aplicabilidade no Brasil contemporâneo. Cadernos EBAPE, 6 (1), 1-12, 2008.

PRIGOGINI, I.Ciência Razão e Paixão. Belém: Eduepa, 2001.

SANDHUSEN, R. L. Marketing Básico. São Paulo: Saraiva, 2003.

SAVITT, R. Historical Research in Marketing. Journal of Marketing, 44 (2), 226-233, 1980.

SETH, J. N.; GARDNER, D. M.; GARETT, D. E. Marketing Theory: Evolution and Evoluation. New York: John Willey \& Sons, 1988.

SURFACE, A., E. Alderson. Marketing. Boston: Ginn and Company, 1940.

THOMPSON, C. J. Modern truth and postmodern incredulity: A hermeneutic deconstruction of the metanarrative of "scientific truth" in marketing research. International Journal of Research in Marketing, v. 10, n. 3, p. 325-338, 1983.

VARGO, S. L., LUSCH, R. L. Envolving to a New Dominant Logic for Marketing. Journal of Marketing, 2004.

WELD, L. D. H. Early Experience in Teaching Courses in Marketing. Journal of Marketing, 8 (2), 380-381, 1941.

WILKIE, W. L., MORE, E. S. Scholary Research in Marketing: Exploring the '4 Eras' of Trought Development. Journal of Public Policy e Marketing, 27 (3), 116-123, 2003.

Rev.Cad.Comun. Santa Maria, v.22, n.1, art 9, p.223 de 224, jan/abr.2018 
CADERNOS DE COMUNICAÇÃO

UNIVERSIDADE FEDERAL DE SANTA MARIA

\section{Sérgio Luís Ignácio de Oliveira}

Pós-doutor em Marketing. Professor do mestrado profissional em alimentos e bebidas na Universidade Anhembi Morumbi.

E-mail: slmarketing@uol.com.br

\section{Leandro Januério de Souza}

Mestre em Administração pela Universidade Paulista. In Memoriam

RECEBIDO EM: 21/01/2017

ACEITO EM: 21/03/2017 